EPJ Web of Conferences 29, 00018 (2012)

DOI: $10.1051 /$ epjconf/20122900018

(C) Owned by the authors, published by EDP Sciences, 2012

\title{
Effect of Fe substitution on structural and magnetic properties of $\mathrm{Pr}_{2} \mathrm{Co}_{7-x} \mathrm{Fe}_{x}$ compounds
}

\author{
R. Fersi ${ }^{\mathrm{a}, 1,2}$, N. Mliki ${ }^{1}$ and L. Bessais ${ }^{2}$ \\ ${ }^{1}$ Laboratoire Matériaux Organisation et Propriétés, Faculté des Sciences de Tunis, Université Tunis \\ El Manar, 2092 Tunis, Tunisie. \\ ${ }^{2}$ CMTR, ICMPE, UMR7182, CNRS - Université Paris 12, 2-8 rue Henri Dunant F-94320 Thiais, \\ France.
}

\begin{abstract}
This work focuses on the synthesis, structure, and magnetic properties of PrCo-Fe compounds. Our previous study of $\mathrm{Pr}_{2} \mathrm{Co}_{7}$ alloys with high coercivity is shown that for samples annealed at $\mathrm{T}_{\mathrm{a}}=800{ }^{\circ} \mathrm{C}$, the main phase is hexagonal of the $\mathrm{Ce}_{2} \mathrm{Ni}_{7}$ type structure. This leads to the formation of a magnetically hard $\mathrm{Pr}_{2} \mathrm{Co}_{7}$ phase; the coercivity being equal to $18 \mathrm{kOe}$ at $293 \mathrm{~K}$ and $23 \mathrm{kOe}$ at $10 \mathrm{~K}$ and important saturation magnetization. These performances are due to the combination of the complementary characteristics of 3d-itinerant and 4f-localized magnetism of Co and Pr, respectively. Its Curie temperature is about $600 \mathrm{~K}$. The aim of this study is to follow the effect of partial substitution of $\mathrm{Co}$ by $\mathrm{Fe}$ on $\operatorname{Pr}_{2} \mathrm{Co}_{7-\mathrm{x}} \mathrm{Fe}_{\mathrm{x}}$ structural and magnetic properties, where $\mathrm{x}=$ $0.25,0.50,0.75$ and 1 . These compounds were synthesized by mechanical alloying. The Rietveld analysis of DRX shows that these intermetallics, annealed at $\mathrm{T}_{\mathrm{a}}=700{ }^{\circ} \mathrm{C}$, adopt mainly hexagonal $\mathrm{Ce}_{2} \mathrm{Ni}_{7}$ type structure with $\mathrm{P}_{3} / \mathrm{mmc}$ group space. Moreover, it points out a lattice expansion along the $\mathrm{c}$ axis after Fe substitution for Co. Furthermore, these hexagonal phases possess magnetic properties more attractive than $\mathrm{Pr}_{2} \mathrm{Co}_{7}$, the Curie temperatures are higher than $\mathrm{Pr}_{2} \mathrm{Co}_{7}$ ones and the highest is obtained for $\mathrm{x}=0.5$ where $\mathrm{T}_{\mathrm{C}}=760 \mathrm{~K}$. This increase is due to the well-known electronic effect that invokes the reduction of antiferromagnetic coupling. These phases are particularly promising for permanent magnet applications.
\end{abstract}

\section{Introduction}

In recent years, the rare-earth-transition metal intermetallic compounds have become well established as an important new class of permanent magnet materials [1, 2]. Among these compounds, the $\mathrm{Pr}_{2} \mathrm{Co}_{7}$ alloy is currently one of the most promising. It has a high Curie temperature, $\mathrm{T}_{\mathrm{C}}=600 \mathrm{~K}$, and an uniaxial magnetocrystalline anisotropy. In addition, the study of extrinsic magnetic properties of the $\mathrm{Pr}_{2} \mathrm{Co}_{7}$ compound revealed the existence of a large coercive field of about $18 \mathrm{kOe}$ at $293 \mathrm{~K}$ and $23 \mathrm{kOe}$ at $10 \mathrm{~K}$, a high remanent magnetization and an important saturation magnetization $\mathrm{M}_{\mathrm{S}}$ [3]. These performances are due to the combination of the complementary characteristics of 3d-itinerant and 4f-localized magnetism of $\mathrm{Co}$ and the rare earth $(\mathrm{Pr}, \mathrm{Sm}, .$.$) ,$

\footnotetext{
a e-mail : FERSI@glvt-cnrs.fr
} 
respecively [4]. The reason for the high $\mathrm{T}_{\mathrm{C}}$ is due to the predominance of the interactions Co-Co [5, $6]$.

In this paper, we report crystal structure and magnetic properties of $\operatorname{Pr}_{2} \mathrm{Co}_{7-\mathrm{x}} \mathrm{Fe}_{\mathrm{x}}$ compounds obtained when cobalt is substituted by iron in $\mathrm{Pr}_{2} \mathrm{Co}_{7}$. Substitution will change the local environment of neighboring atoms and therefore the exchange interaction they undergo.

\section{Experiments}

The $\operatorname{Pr}_{2} \mathrm{Co}_{7-\mathrm{x}} \mathrm{Fe}_{\mathrm{x}}(\mathrm{x}=0.25,0.5,0.75,1)$ alloys were prepared by high-energy ball milling. An excess of Praseodymium powder was used in order to maintain an overpressure of Pr on the sample. The samples were examined by means of X-ray powder diffraction (XRD) using a Brucker diffractmeter with $\mathrm{Cu} \mathrm{K}_{\alpha}$ radiation. The XRD data were used for structure refinement were collected in a step-scan mode with a sampling time of $22 \mathrm{~s}$ and a sampling step of $0.04^{\circ}$ in the $2 \theta$ range of $25-80^{\circ}$. An internal Si standard (NBS, SRM 640) was used to measure the unit cell parameter with an accuracy of $\pm 1 \times 10^{-4} \mathrm{~A}$. The pattern refinement was performed with the FULLPROF computing code based on the Rietveld technique, in the assumption of Thompson-Cox-Hastings line profile [7, 8]. The goodness-of-fit indicators $\mathrm{R}_{\mathrm{B}}$ and $\chi_{2}$ are calculated as usual and described earlier [9]. The magnetization was measured using a differential sample magnetometer (MANICS). When necessary, the samples were sealed in silica tubes to avoid oxidation upon heating. Thermomagnetic data were measured under an applied field of 1000 Oe with a heating rate of $10 \mathrm{~K} / \mathrm{min}$. The Curie temperature $\mathrm{T}_{\mathrm{C}}$ was determined from the M-T curves by extrapolating the linear part of the M-T curve and finding the temperature values of the intersection with the extended baseline $[10,11]$. For magnetic hysteresis measurements at $\mathrm{T}=293 \mathrm{~K}$, we used a Physical Properties Measurement System (PPMS) Quantum Design equipment in fields up to $9 \mathrm{kOe}$.

\section{Results and discussion}

\subsection{Structure analysis}

The XRD patterns and the corresponding Rietveld analysis of the $\operatorname{Pr}_{2} \mathrm{Co}_{7-\mathrm{x}} \mathrm{Fe}_{\mathrm{x}}$ compounds, annealed at $\mathrm{T}_{\mathrm{a}}=700{ }^{\circ} \mathrm{C}$, were systematically done for $\mathrm{x}=0.25,0.5,0.75$ and $\mathrm{x}=1$. Figure 1 shows, as an example, the results obtained for $\mathrm{x}=0.5$. One can see that the $\operatorname{Pr}_{2} \mathrm{Co}_{6.5} \mathrm{Fe}_{0.5}$ phase is present with 98.64\% and adopts mainly a hexagonal $\mathrm{Ce}_{2} \mathrm{Ni}_{7}$-type structure with $\mathrm{P}_{3} / \mathrm{mmc}$ group space. The amounts of oxide are $1.36 \%$ for $\mathrm{Pr}_{2} \mathrm{O}_{3}$.

It is likely that the Fe atoms preferentially reside on the $6 \mathrm{~h}$ sites. In fact, the best agreement factor was obtained with iron located in $6 \mathrm{~h}$ position (Table1). The Rietveld refinement, carried out with a single domain size of diffraction self-consistent with a diameter of $60 \AA$, leads to a $R_{B}$ factor equal to $1.2 \%$. The atom positions and related data obtained by Rietveld refinement of the $\operatorname{Pr}_{2} \mathrm{Co}_{6.5} \mathrm{Fe}_{0.5}$ alloy are reported in Table 2. 


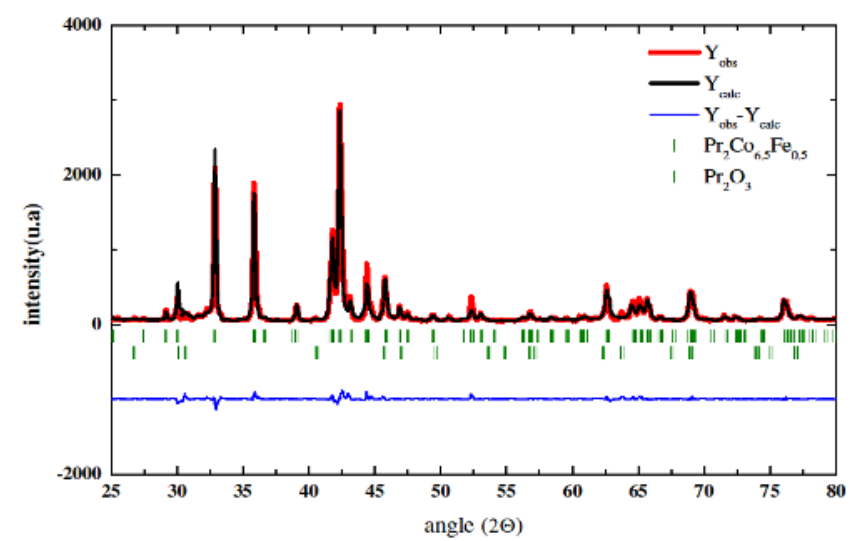

Fig. 1. Rietveld analysis for $\mathrm{X}$-ray diffraction pattern of $\operatorname{Pr}_{2} \mathrm{Co}_{6.5} \mathrm{Fe}_{0.5}$, annealed at $700{ }^{\circ} \mathrm{C}$.

Table 1. The values of $R_{B}$ factor and $\chi_{2}$ from Rietveld refinement for the Fe occupancy in different crystallographic positions.

\begin{tabular}{|c|c|c|c|c|c|}
\hline & $\mathbf{1 2 k}$ & $\mathbf{6 h}$ & $\mathbf{4 f}$ & $\mathbf{4 e}$ & $\mathbf{2 a}$ \\
\hline $\mathbf{R}_{\mathbf{B}}$ & 2.2 & 1.2 & 4.6 & 3.9 & 6.5 \\
\hline$\chi_{\mathbf{2}}$ & 3.7 & 3.2 & 4.5 & 5.3 & 7.8 \\
\hline
\end{tabular}

Table 2. Rietveld refinement results for the atomic positions in a unit cell of the $\mathrm{Pr}_{2} \mathrm{Co}_{6.25} \mathrm{Fe}_{0.5}$ compound.

\begin{tabular}{|c|c|c|c|c|}
\hline Atom & Position & x/a & y/b & z/c \\
\hline Co1 & 12k & 0.1662 & 0.3324 & 0.0854 \\
\hline Co2+Fe & 6h & 0.1647 & 0.3296 & $1 / 4$ \\
\hline Co3 & 4f & $1 / 3$ & $2 / 3$ & 0.1666 \\
\hline Co4 & 4e & 0 & 0 & 0.1670 \\
\hline Co5 & 2a & 0 & 0 & 0 \\
\hline
\end{tabular}

Table 3 shows the variations of parameters obtained in the solid solution $\operatorname{Pr}_{2} \mathrm{Co}_{7-\mathrm{x}} \mathrm{Fe}_{\mathrm{x}}$ for all samples annealed at $700{ }^{\circ} \mathrm{C}$. It appears that the a and c parameters increase slightly with increasing the $\mathrm{Fe}$ content. Then, we observe a unit cell volume expansion. Basically, because Fe has a larger atomic radius than $\mathrm{Co}$, an expansion of lattice is expected with increasing substitution of Co by Fe. Moreover, the variation of c/a ratio with $\mathrm{Fe}$ content suggests that the unit cell expansion is anisotropic and more pronounced in the basal plane.

Table 3. a and c cell parameters, grain size $\Phi$ from Rietveld fit for $\mathrm{Pr}_{2} \mathrm{Co}_{7-\mathrm{x}} \mathrm{Fe}_{\mathrm{x}}$ compounds.

\begin{tabular}{|c|c|c|c|c|c|}
\hline & $\mathbf{0 . 0 0}$ & $\mathbf{0 . 2 5}$ & $\mathbf{0 . 5 0}$ & $\mathbf{0 . 7 5}$ & $\mathbf{1 . 0 0}$ \\
\hline $\mathbf{a}(\AA)$ & $5.068(2)$ & $5.068(3)$ & $5.076(1)$ & $5.079(2)$ & $5.101(3)$ \\
\hline $\mathbf{c}(\mathbf{\AA})$ & $24.457(3)$ & $24.461(5)$ & $24.473(7)$ & $24.465(2)$ & $24.415(5)$ \\
\hline $\mathbf{c} / \mathbf{a}$ & 4.825 & 4.826 & 4.821 & 4.816 & 4.786 \\
\hline $\mathbf{V}\left(\AA^{3}\right)$ & 544.01 & 544.09 & 546.08 & 546.55 & 550.17 \\
\hline $\mathbf{\Phi}(\mathbf{n m})$ & 6 & 7 & 6 & 7 & 8 \\
\hline
\end{tabular}




\subsection{Intrinsic magnetic properties:}

Thermomagnetic analysis indicates that $\mathrm{Pr}_{2} \mathrm{Co}_{7-\mathrm{x}} \mathrm{Fe}_{\mathrm{x}}$ compounds are ferromagnetic with Curie temperature increasing significantly upon iron substitution. The magnetization curves $\mathrm{M}-\mathrm{H}$ of $\mathrm{Pr}_{2} \mathrm{Co}_{7}$ and $\mathrm{Pr}_{2} \mathrm{Co}_{6.5} \mathrm{Fe}_{0.5}$ samples are presented in Figure 3. The temperature dependence of the magnetization for $\mathrm{Pr}_{2} \mathrm{Co}_{7}$ and $\mathrm{Pr}_{2} \mathrm{Co}_{6.5} \mathrm{Fe}_{0.5}$ samples has a unique magnetic phase transition at the Curie temperature. The $\mathrm{T}_{\mathrm{C}}$ of these compounds increases from $600 \mathrm{~K}$ for $\mathrm{Pr}_{2} \mathrm{Co}_{7}$ to $760 \mathrm{~K}$ for $\mathrm{Pr}_{2} \mathrm{Co}_{6.5} \mathrm{Fe}_{0.5}$, then decreases for $\mathrm{x}=0.25$ and $\mathrm{x}=1$ respectively equal to $695 \mathrm{~K}$ and $667 \mathrm{~K}$. This decrease is due to the magnetic dilution indeed. Let's note that the Curie temperature is the result of competition between two effects, the magnetovolumic one related to the distances Co-Co [10] and the electronic effect related to the filling of the $3 \mathrm{~d}$ band of iron [12]. Table 4 shows the lengths of $6 f-$ 6f dumbbells in the rate of substitution for $\operatorname{Pr}_{2} \mathrm{Co}_{7-\mathrm{x}} \mathrm{Fe}_{\mathrm{x}}$ compound. It is found that the variation in lengths of dumbbells is very low. We can conclude that the magnetovolumic effect is negligible and the high Curie temperature variation could be attributed to the electronic effect of substituted iron in $6 \mathrm{~h}$ site which dilutes the negative interactions.

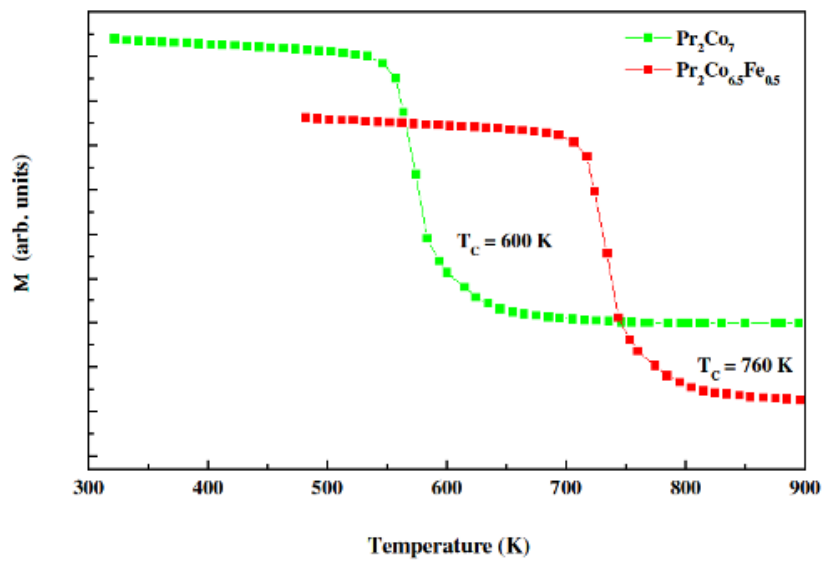

Fig. 2. The Curie temperature of $\mathrm{Pr}_{2} \mathrm{Co}_{7}$ and $\mathrm{Pr}_{2} \mathrm{Co}_{6.5} \mathrm{Fe}_{0.5}$ compounds.

Table 4: Variation of $\mathrm{Co}(6 \mathrm{~h})-\mathrm{Co}(6 \mathrm{~h})$ distances based vs Fe content

\begin{tabular}{|c|c|c|c|c|c|}
\hline $\mathbf{x}$ & $\mathbf{0 . 0 0}$ & $\mathbf{0 . 2 5}$ & $\mathbf{0 . 5 0}$ & $\mathbf{0 . 7 5}$ & $\mathbf{1}$ \\
\hline $\begin{array}{c}\text { Co(6h)- } \\
\text { Co(6h) }\end{array}$ & 2.5091 & 2.5091 & 2.5092 & 2.5092 & 2.5093 \\
\hline
\end{tabular}

The field dependence of magnetization of $\mathrm{Pr}_{2} \mathrm{Co}_{7-\mathrm{x}} \mathrm{Fe}_{\mathrm{x}}$ compounds were measured at $293 \mathrm{~K}$ in a magnetic field ranging from 0 to $90 \mathrm{kOe}$. All samples exhibit ferromagnetic character and tend to approach saturation in a field higher than $20 \mathrm{kOe}$. An example corresponding to $\mathrm{x}=0.5$ is shown in Figure 3. The saturation magnetization, $M_{S}$, is deduced using the saturation approach law $M(H)=M_{S}$ $+\mathrm{a} / \mathrm{H}^{2}$ and converted to the magnetic moment per unit formula. The saturation moment $\mu_{\mathrm{s}}$ of $\operatorname{Pr}_{2} \mathrm{Co}_{7}$ ${ }_{\mathrm{x}} \mathrm{Fe}_{\mathrm{x}}$ increases from 8.32 to $12.28 \mu_{\mathrm{B}} /$ f.u with increasing Fe content from 0 to $\mathrm{x}=1$. Since the atomic moment of transition metal may be underestimated if the crystal-field effect of Pr moment is taken into account, the large atomic moment of the transition metal implies that the compound becomes strong ferromagnetic as the substitution of Fe for Co increases. 


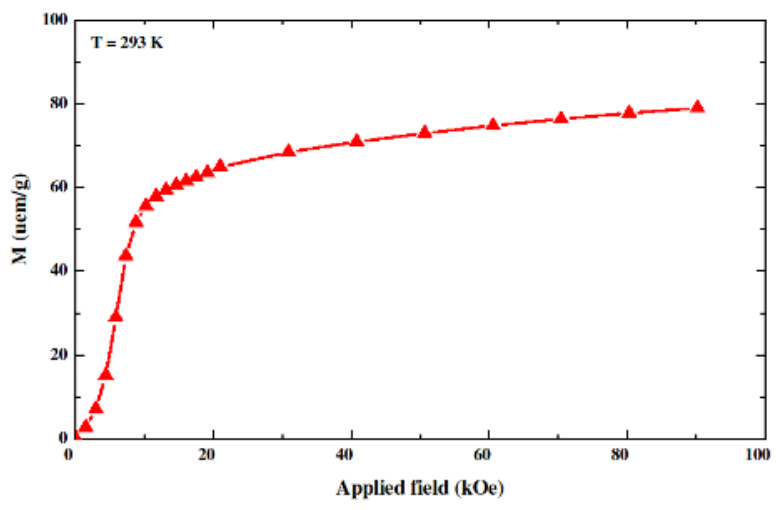

Fig. 3. Field dependence of the magnetic moment of $\operatorname{Pr}_{2} \mathrm{Co}_{6.5} \mathrm{Fe}_{0.5}$ compounds measured at $293 \mathrm{~K}$.

\subsection{Extrinsic magnetic properties: coercivity}

The search for the optimized nanocrystalline state could lead to good extrinsic characteristics. In order to reach the best one, annealing at different temperatures were performed on many samples. For each annealing temperature, a measure $\mathrm{M}(\mathrm{H})$ is performed.

The hysteresis loop of the sample $\mathrm{Pr}_{2} \mathrm{Co}_{6.5} \mathrm{Fe}_{0.5}$ annealed at $800{ }^{\circ} \mathrm{C}$ measured at $293 \mathrm{~K}$ is illustrated in Figure 4.

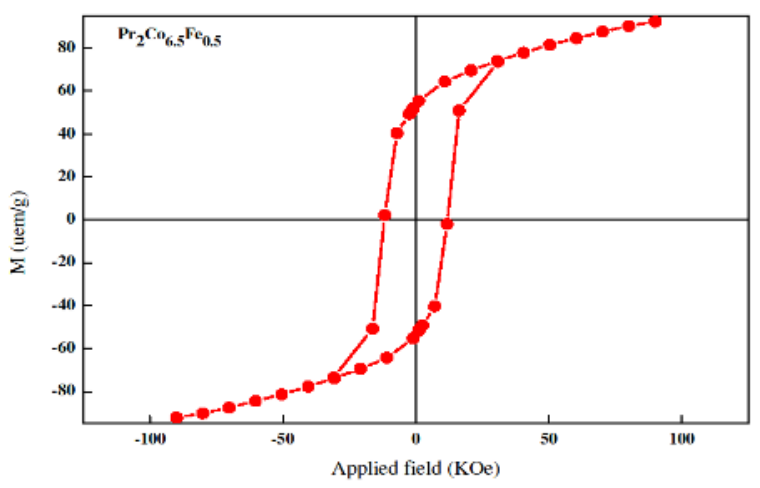

Fig. 4. Hysteresis loop of $\operatorname{Pr}_{2} \mathrm{Co}_{6.5} \mathrm{Fe}_{0.5}$ annealing at $800{ }^{\circ} \mathrm{C}$, measured at $293 \mathrm{~K}$.

The microstructures revealing the best magnetic properties correspond to an annealing temperature ranging between 700 and $900{ }^{\circ} \mathrm{C}$. The better coercivity measured at $293 \mathrm{~K}$ is $\mathrm{H}_{\mathrm{c}}=13 \mathrm{kOe}, \mathrm{Mr}=60$ uem $/ \mathrm{g}$ and $\mathrm{M}_{\mathrm{r}} / \mathrm{M}_{\max }=0.61$ for $\mathrm{x}=0.25$ annealed at $\mathrm{T}_{\mathrm{a}}=700{ }^{\circ} \mathrm{C}$, and $\mathrm{H}_{\mathrm{c}}=11 \mathrm{kOe}, \mathrm{Mr}=57 \mathrm{uem} / \mathrm{g}$ and $\mathrm{M}_{\mathrm{r}} / \mathrm{M}_{\max }=0.68$ for $\mathrm{x}=0.5$ annealed at $\mathrm{T}_{\mathrm{a}}=800{ }^{\circ} \mathrm{C}$. The enhanced remanence $\left(\mathrm{M}_{\mathrm{r}} / \mathrm{M}_{\max }>0.5\right)$ suggests strong exchange interaction between the adjacent crystallites; characteristic of the nanocrystalline state, where the mean grain size is about $8 \mathrm{~nm}$ as determined by analysis Rietveld. These compounds are useful for applications in the field of permanent magnets, due to their high Curie temperature and high coercivity.

\section{Conclusion}

In conclusion, new $\mathrm{Pr}_{2} \mathrm{Co}_{7-\mathrm{x}} \mathrm{Fe}_{\mathrm{x}}$ compounds with $\mathrm{Ce}_{2} \mathrm{Ni}_{7}$-type structure were synthesized. This solid solution is obtained by high energy milling followed by annealing for $30 \mathrm{~min}$. These compounds are ferromagnetic. The Curie temperature increases from $600 \mathrm{~K}$ to $760 \mathrm{~K}$ and the saturation magnetic 
moment increases from 8.32 to $12.28 \mu_{\mathrm{B}} / \mathrm{f}$.u, when $\mathrm{x}$ varies between 0 and 1 . In addition, the study of extrinsic magnetic properties of the $\operatorname{Pr}_{2} \mathrm{Co}_{6.5} \mathrm{Fe}_{0.5}$ compound revealed the existence of a large coercive field about $11 \mathrm{kOe}$ at $293 \mathrm{~K}$, and a high remanent magnetization of the order of $60 \mathrm{emu} / \mathrm{g}$ measured at room temperature for samples annealed at $800{ }^{\circ} \mathrm{C}$. This leads to materials with magnetic properties in high-performance permanent magnets.

\section{References}

1. G. C. Hadjipanayis, J. Magn. Magn. Mater. 200373 (1999)

2. E. F. Kneller and R. Hawig, IEEE Trans. Magn. 27, 3588 (1991)

3. R. Fersi, N. Mliki, and L. Bessais, IOP Conf.Series:Materials Scienceand Engineering. 28, 012014 (2012)

4. A. V. Deryagin, J. Phys. C5, 165 (1979)

5. R. Lemaire, Cobalt 33. 201 (1966)

6. K. Konno, H. Ido, S. F. Cheng, S. G. Sankar, and W. E.Wallace, J. Appl. Phys. 73(10), 5929 (1993)

7. H. Rietveld, J. Appl. Crystallogr. 2, 65 (1969)

8. J. Rodrguez-Carvajal, Physica. B 192, 55 (1993)

9. L. Bessais and C. Djega-Mariadassou, Phys. Rev. B 63, 054412 (2001)

10. S. Khazzan, N.Mliki, and L. Bessais, J. App. Physics. 105, 103904 (2009)

11. L. Bessais, C. Djega-Mariadassou, and P. Beaunier, J. App. Physics. 99, 093906 (2006)

12. C. Djga-Mariadassou, L. Bessais, and A. Nandra, Physical Review. B 68, 024406 (2003) 